\title{
O discurso de promoção do Prêmio Nacional das Artes e sua alusão ao regime nazista alemão
}

\section{Paulo Victor Arouche Costa Leite}

Universidade Federal do Maranhão, Programa de Pós-Graduação em História Social, São Luís, MA, Brasil ORCID: https://orcid.org/0000-0003-1216-1533.

\section{Ingrid Pereira de Assis}

Universidade Federal do Tocantins, Palmas, TO, Brasil.

ORCID: https://orcid.org/0000-0002-1568-0788.

\section{Resumo}

O objetivo do artigo é identificar as similaridades e aproximações entre o discurso proferido pelo então secretário especial da Cultura do Brasil, Roberto Alvim, e as particularidades do regime nazista, a partir de um aporte teórico voltado à compreensão das peculiaridades discursivas. Aciona-se, neste artigo, a metodologia da Análise do Discurso, de forma menos sistemática e mais ensaística, amparando-se em proposições teóricas acerca da construção discursiva para elaborar uma reflexão interdisciplinar, compreendendo aspectos históricos e comunicacionais. Os procedimentos metodológicos empregados foram: a coleta documental do vídeo do pronunciamento analisado; a decupagem e a revisão bibliográfica sistemática, para formar o aporte teórico da investigação. O corpus da análise é, portanto, o vídeo de divulgação do Prêmio Nacional das Artes. Dentre as conclusões, aponta-se a identificação de elementos visuais e verbais que remetem ao discurso do regime totalitário alemão, utilizando inclusive o recurso da paráfrase.

\section{Palavras-chave}

Discurso; Nazismo; Fascismo; Secretaria da Cultura; Roberto Alvim 


\section{Introdução}

No dia 16 de janeiro de 2020, Roberto Alvim, secretário especial da Cultura do Brasil, de novembro de 2019 a janeiro de 2020, ao anunciar o que viria a ser o "Prêmio Nacional das Artes", afirmou que o presidente da República, Jair Bolsonaro, pediu a promoção de uma cultura que não destruísse a juventude, mas que "a salvasse". Pouco tempo após a transmissão, o anúncio passou a ser fortemente criticado em plataformas de redes sociais, principalmente por sua semelhança com a estética do regime nazista alemão (1933-1945) e por fazer uma paráfrase de um discurso do ministro de Adolf Hitler da Propaganda da Alemanha Nazista, Joseph Goebbels, antissemita radical e um dos idealizadores do nazismo. Logo após a repercussão negativa do anúncio, que levou tanto o nome de Roberto Alvim quanto de Joseph Goebbels para os assuntos mais comentados do Twitter no Brasil, o secretário foi exonerado.

Considerando tais fatos, o objetivo deste artigo é dissecar as familiaridades entre o discurso proferido por Roberto Alvim e as particularidades do regime totalitário alemão, identificando possíveis aproximações, a partir de um aporte teórico voltado à análise das peculiaridades discursivas. Para isso, faz-se uso da metodologia da Análise do Discurso, não em sua proposta mais sistemática, mas sim, em um formato mais ensaístico, amparando-se em proposições teóricas de pesquisadores do discurso para construir uma reflexão que é, sobretudo, interdisciplinar, abarcando aspectos históricos e comunicacionais. Sendo assim, os procedimentos metodológicos empregados foram: a coleta documental do vídeo analisado; a decupagem e a revisão bibliográfica sistemática, para o aporte teórico da investigação. 0 corpus da análise é, portanto, o vídeo de divulgação do prêmio supracitado.

Para realizar tal exame, primeiro serão detalhados os aspectos relevantes sobre discurso que auxiliam teoricamente neste processo de análise, para, em seguida, iniciar a apreciação do objeto investigado, não deixando de recorrer às informações históricas para a compreensão do contexto, tanto de desenvolvimento do regime nazista, quanto de proferimento do discurso em questão.

\section{Análise do discurso}

Primeiro, faz-se importante saber de que forma o discurso é compreendido aqui, para depois seguir para a análise. Parte-se da concepção de que o discurso é formado a partir de um 
conjunto de enunciados que são proferidos em dada condição histórica. Portanto, não há discurso desconectado da história:

Chamaremos de discurso um conjunto de enunciados, na medida em que se apoiem na mesma formação discursiva; ele é constituído de um número limitado de enunciados, para os quais podemos definir um conjunto de condições de existência [...] (FOUCAULT, 1997, p. 135).

Tais condições de existência são históricas, portanto, os discursos e as respectivas interdições que os atravessam desvelam suas relações com o desejo e as disputas de poder, ou seja, a política, e são, ao mesmo tempo, objeto desta disputa, como bem frisa Foucault (2001):

Nisto não há nada de espantoso, visto que o discurso - como a psicanálise nos mostrou - não é simplesmente aquilo que manifesta (ou oculta) o desejo; é, também, aquilo que é objeto do desejo; e visto que - isto a história não cessa de nos ensinar - o discurso não é simplesmente aquilo que traduz as lutas ou os sistemas de dominação, mas aquilo por que, pelo que se luta, o poder do qual nos queremos apoderar. (FOUCAULT, 2001, p. 10).

Destaca-se, também, que a própria história é uma construção discursiva, amparada, como defende Paul Veyne, na aplicação das Ciências Morais e Políticas, e como tal apresenta arbitrariedades e inconsistências. Desse modo, na análise do discurso feita neste artigo, por mais que se recorra a elementos de outro momento histórico para compreendê-lo, empenhase o esforço de não esquecer que o contexto em que este se insere também é outro. Além disso, convém reforçar que este artigo, por si só, é a construção de um discurso atravessado por suas próprias condições de existência:

[...] por uma estranha ilusão, crê-se que a História não se repete; sob o pretexto de que um fato histórico é individual, imagina-se que ele seja singular. No entanto, numerosos fatos históricos são quase gêmeos idênticos - assemelham-se como duas gotas d'água; não deixam de ser, por causa disso, dois indivíduos distintos e, quando o historiador faz o recenseamento, considera-os como tais. Apenas aos olhos de um sociólogo eles recairiam numa só e mesma categoria. (VEYNE, 1983, p. 41).

Portanto, para gerar a interpretação de um discurso, faz-se necessário compreender os elementos no entorno do que foi proferido, a partir de um olhar histórico, sociológico e comunicacional. Foca-se não só no que disse, mas, também, quem disse, de que modo disse e em que contexto, vinculando o texto à sua exterioridade. 
Nem, de um lado, só a língua, nem de outro só a situação-lá, o fora. Observando a materialidade do texto, não abandono o exterior específico (o real da história) mas o considero atravessado pelo exterior constitutivo (o interdiscurso). (ORLANDI, 2003, p. 4).

Desse modo, ao analisar o que estava sendo proferido pelo então secretário de cultura do governo de Jair Bolsonaro, é importante reconstruir o cruzamento entre este discurso e o do Joseph Goebbels, descamando o significado da escolha de tais palavras e a carga ideológica que elas trazem, pois, como frisa Orlandi (2003, p. 5), a paráfrase é um "fenômeno semântico que produzido por uma substituição contextual, produz um deslizamento de sentido". É preciso ter ciência do texto parafraseado para chegar ao sentido ideológico que um texto de divulgação de um edital de cultura carrega consigo e, também, compreender o novo contexto histórico no qual tal discurso se (re)inventa e (re)insere.

Além disso, o sentido do texto não está presente apenas na linguagem verbal proferida. 0 texto imagético, ainda mais em uma produção audiovisual, é de fundamental importância para a compreensão da paráfrase construída no vídeo de divulgação do Prêmio Nacional das Artes. A imagem analisada por este artigo é, ao mesmo tempo, uma paráfrase e uma metáfora, pois como explica Martins (2013, p. 3): “[...] uma imagem é, em simultâneo, uma metáfora, porque aproxima duas coisas diferentes; e uma descrição, visto que revela uma visão do mundo, real ou não real, representável ou irrepresentável pela racionalidade".

Enquanto uma representação, a imagem consiste em um signo e, deste modo, é atravessada por particularidades culturais. Isto leva a concluir que não há uma gramática universal para compreendê-la. "A linguagem visual não é - apesar de suposições contrárias transparente e universalmente entendida; é culturalmente específica" (KRESS; VAN LEEUWEN, 2006, p. 4)1. Ancorados em Barthes, os autores defendem que o significado da imagem está sempre relacionado ao texto verbal que a acompanha, seja ele oral ou escrito. Isso porque as imagens são muito polissêmicas, possibilitando diversas interpretações. Sendo assim, "para chegar a um significado definido, a linguagem deve vir em socorro. 0 significado visual é indefinido demais" (KRESS; VAN LEEUWEN, 2006, p. 18)22. Disto já é possível extrair que os textos verbo-visuais estão imbricados e, juntos, fornecem significados, paráfrases e metáforas. Feitas essas ponderações teóricas a respeito dos discursos, no próximo tópico

\footnotetext{
1 No original: "Visual language is not - despite assumptions to the contrary - transparent and universally understood; it is culturally specific" (KRESS; VAN LEEUWEN, 2006, p. 4).

2 No original: "To arrive at a definite meaning, language must come to the rescue. Visual meaning is too indefinite" (KRESS; VAN LEEUWEN, 2006, p. 18).
} 
serão dissecadas essas construções de paráfrases e metáforas de forma a extrair o significado do discurso proferido e identificar possíveis semelhanças com o discurso e, consequentemente, com a ideologia nazista.

\section{Discurso do Prêmio Nacional das Artes}

Sentado e enquadrado no centro do vídeo, Roberto Alvim tem a bandeira nacional à direita, a Cruz de Lorena3 à esquerda e a foto oficial do presidente Jair Bolsonaro acima de sua cabeça (conforme imagem abaixo). A música usada como background (BG) do discurso foi o prelúdio de Lohengrin, de Richard Wagner (1813-1883), importante compositor do romantismo alemão que, por razões óbvias, não era nazista, porém, amplamente conhecido pelo seu antissemitismo e pela ideia de uma "arte total" capaz de retratar a grandeza mitológica do passado alemão. Este ideal foi apropriado pelo movimento nazista para construção de um projeto de retorno ao que seria a Alemanha gloriosa do passado, em um movimento de saudosismo e idealização do passado do país.

Figura 1 - Print do vídeo do discurso de Roberto Alvim

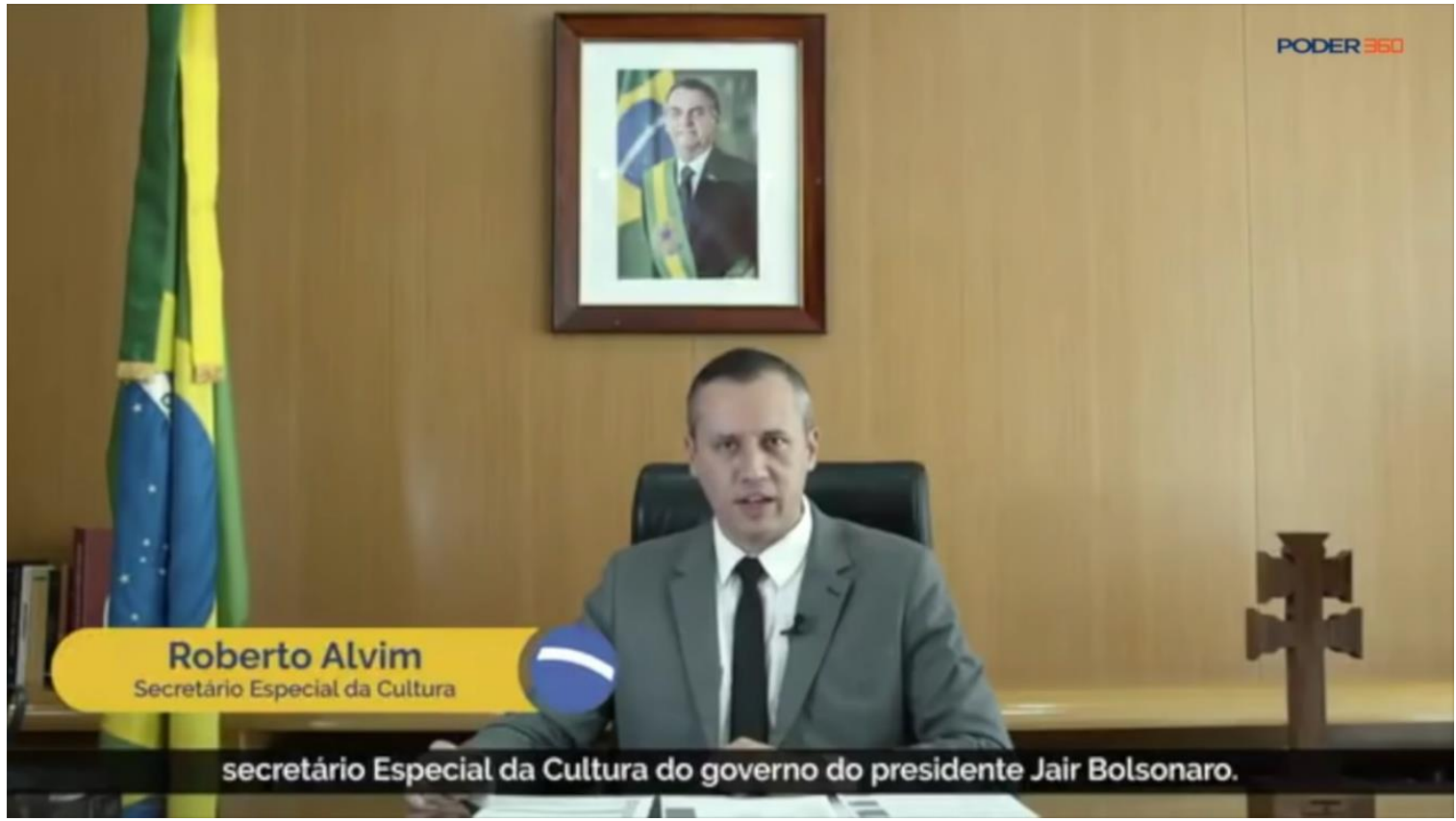

Fonte: Canal do Youtube do Poder 360 (2020).

3 Consiste em um símbolo cristão de origem espanhola. 
Embora fosse um anúncio sobre as novas diretrizes de políticas de incentivo para arte e cultura brasileira, não há nenhum signo - à exceção da bandeira nacional - que faça referência à cultura do Brasil, conhecida por sua diversidade, resultado da mistura constante e (re)significação da cultura dos povos originários e dos mais diferentes processos migratórios. A predominância de símbolos eminentemente europeus, da cruz à música, remete a um esforço de vinculação afetiva e imaginária a uma ideia de superioridade civilizacional europeia, o que reforça a percepção de uma mentalidade colonizada na idealização e execução da peça audiovisual, que pode também ser projetada ao público-alvo de tal produção.

A necessidade desses setores de reafirmar esse passado idealizado a partir de raízes ibéricas se dá porque o discurso medieval${ }^{4}$ oferece uma série de preconceitos tais como: preconceito étnico, homofobia, islamofobia e o machismo. Faz-se importante definir aqui que tais preconceitos não podem ser meramente reduzidos a seus aspectos ideológicos. Tratam-se de sistemas complexos de dominação, que se fundamentam nos aspectos étnicos ou raciais, de orientação sexual, ou identidade de gênero, e religiosos para estabelecer ou fortalecer uma desigualdade que beneficia os dominantes (VAN DIJK, 1993; BOURDIEU, 2010).

Especificamente no caso do racismo, Van Dijk (2001, p. 192) explica que o seu sistema é composto por um subsistema social e outro cognitivo: "O subsistema social é constituído por práticas sociais discriminatório no nível local (micro) e por relacionamentos com abuso de poder por grupos organizações e instituições dominantes". Este abuso de poder está diretamente relacionado às práticas de dominação, que também se dão na definição social do corpo, da sexualidade e do gênero. Vive-se em um mundo baseado em uma sociodicéia masculina e, sobretudo, branca, que naturaliza essa dominação.

A força particular da socidicéia masculina lhe vem do fato de ela acumular e condensar duas operações: ela legitima uma relação de dominação inscrevendo-a em uma natureza biológica que é, por sua vez, ela própria uma construção social naturalizada. (BOURDIEU, 2010, p. 33).

Portanto, a filiação a esse passado idealizado, branco, cristão e patriarcal sugere uma nova cruzada, seja contra o "globalismo", a "ideologia de gênero" - ou o velho fantasma do comunismo - sob o pretexto de restabelecimento de valores idealizados enquanto

\footnotetext{
4 A palavra medieval aparece aqui porque esse período histórico ficou marcado por práticas intolerantes que admitiam inclusive o emprego da força para converter as pessoas ao cristianismo, em particular judeus e mulçumanos (GUISALBERTI, 2011).
} 
tradicionais da família brasileira ou modelos biológicos do ser humano. A busca é pela legitimação de uma agenda que domina esses grupos sociais colocados como opositores, a partir da ideia de uma cultura de "salvação" da juventude e de esquecimento de que:

[...] aquilo que convencionamos chamar de Brasil (um país, uma nação, uma sociedade, uma cultura etc.) é o resultado simbólico e material (objetivo) de séculos de disputas e guerras de conquista territorial, de genocídios de populações originárias, imigrações voluntárias e forçadas (escravos africanos), da exploração inconsequente de recursos naturais e humanos, da consolidação de propriedades da metrópole portuguesa que, eventualmente, passou às mãos de uma aristocracia luso-brasileira e oligarquias familiares de latifundiários escravocratas reinóis e maçons. (FREIXO, 2019, p. 60).

Portanto, o vídeo de divulgação do "Prêmio Nacional das Artes" evidencia uma necessidade de promover uma política de identidade para o patriarcado branco, oriundo de uma aristocracia em crise. Defende-se que "patriarcado branco" também é um lugar de discurso e identificação, embora tenha uma realidade socioeconômica tangível. Este grupo social, para manter as posições de poder, acaba por acionar estratégias de fortalecimento dessa posição de privilégio, que perpassam a dominação dos demais indivíduos ou grupos sociais não possuidores dos mesmos capitais.

Os agentes sociais estão inseridos na estrutura e em posições que dependem do seu capital e desenvolvem estratégias que dependem, elas próprias, em grande parte, dessas posições, nos limites de suas disposições. Essas estratégias orientam-se seja para a conservação da estrutura seja para a sua transformação, e pode-se genericamente verificar que quanto mais as pessoas ocupam uma posição favorecida na estrutura, mais elas tendem a conservar ao mesmo tempo a estrutura e sua posição [...] (BOURDIEU, 2004, p. 29).

Em parte, esta dominação funciona porque há um convencimento e uma naturalização acerca da posição de inferioridade do outro, como já explicado. Sendo assim, quando se menciona o "patriarcado branco", sabe-se que não necessariamente apenas homens brancos e privilegiados reproduzem os discursos de fortalecimento da dominação deste grupo, mas, até mesmo negros, mulheres e homossexuais podem desenvolver uma identificação imaginária e reafirmar os valores sociais já absorvidos ao longo da sua trajetória de vida, seja pela profundidade da dominação sofrida por este agente ou para negar o pertencimento a determinado segmento social menos reconhecido. Por esse motivo, é possível identificar um 
comportamento de concordância com este viés conservador, que parafraseia discursos nazistas, por parte de alguns agentes sociais, mesmo indo de encontro a suas próprias condições de raça, classe e gênero.

Estratégias simbólicas de investimento são todas as ações que visam preservar ou aumentar o capital de reconhecimento (em diferentes sentidos do termo), privilegiando a reprodução de esquemas de percepção e valorização mais favoráveis aos seus proprietários e produzindo ações suscetíveis se eles são apreciados favoravelmente de acordo com essas categorias (por exemplo, mostrando força para não precisar usá-la). (BOURDIEU, 2002, p. 15)5.

O discurso de Roberto Alvim está vinculado a uma série de condutas que foram banalizadas na campanha eleitoral de 2018 - e mesmo antes dela - e que se perpetuam nos canais de comunicação do governo. Ao identificarem a semelhança do discurso do secretário com o do ministro de Adolf Hitler, a justificativa dada por Roberto Alvim em suas redes sociais foi a de que seria uma "coincidência retórica". Faz-se necessário pontuar que, segundo Brito (2016, p. 211), "o discurso não é nunca individual, pois, em cada enunciado, em cada palavra, ressoam duas vozes, a do eu e a do outro". A autora se ampara em Authier-Revuz (1990) para ponderar que existe uma heterogeneidade que é constitutiva da linguagem, que, para ser compreendida, faz-se necessário recorrer à noção de inconsciente da psicanálise freudo-lacaniana. Reduzir o discurso de Alvim à uma coincidência retórica é ignorar todas as relações, inclusive inconscientes, que geram uma polifonia discursiva6. "Ao assumir os postulados de Authier-Revuz [...] sobre a heterogeneidade enunciativa, assumimos que a linguagem é o ambiente do não-Um, do heterogêneo, do múltiplo, do plural, da alteridade, do 'outro'” (BRITO, 2016, p. 208). Tendo estes aspectos destacados, segue-se para a primeira parte do discurso:

A Cultura é base da Pátria. Quando a Cultura adoece, o povo adoece junto. É por isso que queremos uma Cultura dinâmica e, ao mesmo tempo, enraizada na nobreza de nossos mitos fundantes. A Pátria, a família, a coragem do

\footnotetext{
5 No original: "Las estrategias de inversión simbólica son todas las aciones que tienen por objeto conservar o aumentar el capital de reconocimiento (en los diferentes sentidos del término), privilegiando la reprodución de los esquemas de percepción y de apreciación más favorables a sus propietarios y produciendo las acciones susceptibles de ser apreciadas favorablemente según esas categorías (por ejemplo mostrar la fuerza para no tener que servirse de ella) (BOURDIEU, 2002, p. 15).

6 Authier-Revuz (1990) utiliza o termo heterogeneidade em oposição à noção de polifonia bakhtiana e a de polifonia ducrotiana. Sua proposta é de uma heterogeneidade constitutiva da linguagem e articulada ao conceito de dialogismo bakhtiniano. Para esta autora, mesmo em uma aparente linearidade do discurso de uma só voz, outras vozes ecoam. 0 diferencial da proposta desta autora perante a teoria bakhtiniana está na incorporação da psicanálise freudo-lacaniana, com a noção de inconsciente, à ideia de heterogeneidade.
} 
povo e sua profunda ligação com Deus amparam nossas ações na criação de políticas públicas. As virtudes da fé, da lealdade, do autossacrifício e da luta contra o mal serão alçadas ao território sagrado das obras de Arte. (ALVIM, 2020, grifos nossos) ${ }^{7}$.

De maneira abrangente, a cultura abarca todas as realizações materiais e imateriais de um povo e é espontaneamente dinâmica, uma vez que muda ao longo do tempo, incorporando novos elementos, abandonando e/ou ressignificando antigos. A cultura também tem o significado muito próximo do ato de educar, ou seja, representa aquilo que um povo transmite aos seus descendentes para garantir sua perpetuação, como a língua e a religião (SILVA; SILVA 2015). Em um outro sentido, mas ainda relacionado aos demais, usa-se à palavra cultura para designar a produção artística e intelectual, que é justamente o pano de fundo do discurso em questão. Quando se fala em adoecimento da cultura, pretende-se implementar uma "política pública de salvação", que traga a cultura a um estado que supostamente já lhe foi próprio, "saudável", por esse motivo, uma ideia de retorno a um passado idealizado (mitos fundantes), onde a família, a Pátria e Deus ocupam a centralidade da produção cultural. Qual o papel de cada um desses elementos?

Primeiro, a família tem relação com as ideias de valores tradicionais, que pregam a submissão das mulheres aos maridos e desprezam outros arranjos familiares, especialmente, os homoafetivos, que só muito recentemente passaram a ser socialmente e legalmente reconhecidos8. Segundo: a Pátria é o elemento nacionalista que vincula o atual governo com o período da Ditadura Militar, no qual tais elementos foram amplamente utilizados (a bandeira nacional, hinos, o reforço da autoridade etc.) e, como consequência disso, uma militarização da conduta da população contra os inimigos que são construídos discursivamente: o partido de oposição, a imprensa, os artistas, a comunidade científica, em suma, o dissenso. Por último, mas não menos importante, Deus aparece com destaque porque a política é uma política de salvação. Ela é messiânica, não se baseia em parâmetros científicos, ela exige confiança de que os eleitos pelo povo, "e por Deus", conduzirão os fiéis de volta ao caminho correto. Além disso, alimenta o antagonismo político - vale lembrar do par amigo/inimigo de Carl Schmitt9 - por isso, a construção discursiva do inimigo, revestida da imagem de uma "luta contra o

7 ALVIM, Roberto. Secretário da cultura, Roberto Alvim cita ministro nazista em pronunciamento. Canal do Poder 360 no Youtube, 2020.

8 Em 2011, o Supremo Tribunal Federal (STF) declarou como legal a união civil entre pessoas do mesmo sexo. No ano de 2013, o Conselho Nacional de Justiça (CNJ) publicou uma resolução permitindo aos cartórios o registro de casamentos homoafetivos.

9 Jurista e filósofo político alemão. Expoente do decisionismo jurídico, Schmitt defendia que o soberano é aquele determina a decisão política fundamental. A exceção seria a essência da soberania e o antagonismo amigo/inimigo seria fundamento político/normativo da instituição e conservação de um ordenamento jurídico (MACEDO JR., 2011). 
mal", em oposição àqueles que não compartilham os supostos valores originários, daí a ideia de uma Cruzada do século XXI.

Um dos elementos mais importantes na primeira parte do discurso é a ideia de auto sacrifício. Pode-se relacioná-la a uma série de medidas e reformas em curso que prejudicam a parcela mais vulnerável da população, seja pela precarização do trabalho, violência policial, fim do estado de bem-estar social por meio do ataque à previdência social. Nisso reside uma das diferenças fundamentais entre o fascismo dos dias atuais e o fascismo histórico do entreguerras 10 . Na primeira metade do século XX, o Estado era central na estratégia fascista de mobilização social e como centro promotor da atividade econômica e industrial. Hoje, presencia-se o apelo ao autossacrifício individual e coletivo em nome da economia neoliberal e a política de salvamento dos interesses capitalistas. É preciso, portanto, sacrificar-se para que um projeto de Estado mínimo nos direitos sociais - e máximo em repressão - possa resolver os problemas dos brasileiros. Indo mais a fundo, a ideia de autossacrifício aparece em autores do entreguerras, como no ensaio de Ernst Jünger (1895-1998), O Trabalhador. Domínio e Figura (Der Arbeiter. Herrschaft und Gestalt), de 1932. Neste texto, segundo o historiador Victor Coelho (2017), Jünger sistematiza uma Lebensphilosophie ("filosofia de vida") bélica, a partir da exaltação do mundo industrial moderno como uma oportunidade de uma nova totalidade, com vistas a superar a crise política e espiritual da Alemanha:

[...]com Jünger e sua figura (Gestalt) ou tipo do trabalhador, temos uma solução no ambiente político-intelectual da modernização conservadora alemã: a subjetividade individual deve se sacrificar em prol da mobilização total da técnica, no espaço industrial e na guerra. [...] a racionalidade iluminista é trocada pela "linguagem sem palavras" da técnica e esta, por sua vez, deve ser encarada em sua dimensão cultual [de culto, adoração]. Enfim, a totalidade ideal, enquanto "terceira instância" (Humboldt) entre os cidadãos e a contingência, daria lugar novamente a uma totalidade ontológica: a totalidade do trabalho; e a natureza idílica, índice da totalidade perdida e presente nos movimentos neorromânticos reacionários, dá lugar à natureza planificada do trabalho. (COELHO, 2017, p. 253).

O contexto da Alemanha da década de 1930 é diferente do Brasil atual, no entanto, é possível perceber apropriações. Ainda que não tenha se filiado ao Partido Nazista, Jünger

10 Muito se discute sobre a pertinência conceitual do fascismo a esse novo contexto, sucede que ao mesmo tempo que é necessário rigor técnico e analítico, a dinâmica social e política não permite que o conceito seja compreendido tal qual foi formulado, o mesmo ocorre com capitalismo e democracia, que apesar das alterações significativas ao longo do tempo continuam sendo utilizados. Os "ismos", que são conceitos de compensação temporal, isto é, por serem baseados apenas parcialmente na experiência, possuem uma abertura que pode ser preenchida de acordo com as expectativas políticas do tempo histórico (KOSELLECK, 2012). 
colaborou intelectualmente para escalada do fascismo na Alemanha. Naquele período, vários intelectuais alemães buscaram aliar a técnica moderna ao fundamento da Kultur11, em detrimento da razão iluminista, promovendo um projeto político tradicionalista e autoritário. Jünger, assim como outros intelectuais, via na tecnologia um caminho para solucionar a "crise de decadência" e "declínio cultural", portanto, uma ideia muito semelhante do discurso de Alvim quando ele diz "A Cultura é base da Pátria. Quando a Cultura adoece, o povo adoece junto". A noção de doença está intimamente relacionada ao declínio, o que se aproxima da percepção da obra $O$ declínio (ou decadência) do Ocidente (1918), de Oswald Splenger. Esse ideário também aproxima Jünger de outros autores, como Heiddeger e Carl Schmitt, criando um cenário da intelectualidade alemã, que ficou conhecido como "Movimento Revolucionário Conservador" ou Revolução Conservadora. No direito, por exemplo, especialmente com Carl Schmitt, é rejeitado o princípio liberal da liberdade individual como fundamento da política e do direito, que também se faz presente no discurso de Roberto Alvim:

\footnotetext{
Nossos valores culturais também conferem grande importância à harmonia dos brasileiros com sua terra e natureza, assim como enfatizam a elevação da nação e do povo acima de mesquinhos interesses particulares. A cultura não pode ficar alheia às imensas transformações intelectuais e políticas que estamos vivendo. (ALVIM, 2020, grifos nossos).
}

A Revolução Conservadora pretendia alcançar uma terceira via, uma vez que negava o "hamletismo político" (Carl Schmitt) da democracia liberal e o caráter internacionalista do marxismo. 0 indivíduo deveria estar conformado a um tipo ideal (Gestalt) - para Jünger o tipo do trabalhador12 -, sacrificando sua subjetividade individual em função de uma mobilização total ou, nas palavras de Roberto Alvim: "[...] a elevação da nação e do povo acima de mesquinhos interesses particulares". O secretário segue enfatizando que a cultura não pode estar alheia "[...] as imensas transformações intelectuais e políticas que estamos vivendo", o que remete à sensação de mobilização total, muito similar ao conceito de "Movimento, Estado, Povo", do período nazista, o que fica ainda mais evidente ao comparar o terceiro momento do discurso do secretário de cultura, que parafraseia de forma mais aproximada o discurso do

\footnotetext{
11 Cultura em alemão, designa uma série de atributos característicos da formação espiritual do povo, elemento valorizado, sobretudo, pelo romantismo do século XIX e correntes de pensamentos nacionalistas.

12 "A ordem jesuíta e o exército prussiano, além dos cavaleiros teutônicos, haviam sido elencados em $O$ trabalhador como modelos de uma vida espartana que se faria presente agora, mobilizando o mundo, na paisagem das oficinas - e por isso seriam então como que prefigurações da figura ou tipo do trabalhador" (COELHO, 2017, p. 252).
} 
ministro da propaganda de Hitler, Joseph Goebbels, como é possível observar no quadro comparativo abaixo:

Quadro 1 - Comparação do discurso de Roberto Alvim e de Joseph Goebbels

\begin{tabular}{|c|c|}
\hline Roberto Alvim & Joseph Goebbels \\
\hline Secretário da cultura do governo Bolsonaro & Ministro da propaganda de Hitler \\
\hline 16 de janeiro de 2020 & 1933 \\
\hline $\begin{array}{l}\text { A arte brasileira da próxima década será } \\
\text { heroica e será nacional; será dotada de grande } \\
\text { capacidade de envolvimento nacional e será } \\
\text { igualmente imperativa, posto que } \\
\text { profundamente vinculada às aspirações } \\
\text { urgentes do nosso povo - ou então não será } \\
\text { nada. Ao país a que servimos, só interessa uma } \\
\text { Arte que cria sua própria qualidade a partir da } \\
\text { nacionalidade plena, e que tem significado } \\
\text { constitutivo para o povo para o qual é criada } \\
\text { (ALVIM 2020, grifos nossos). }\end{array}$ & $\begin{array}{l}\text { A arte alemã da próxima década será heroica, } \\
\text { será ferreamente romântica, será objetiva e livre } \\
\text { de sentimentalismo, será nacional com grande } \\
\text { páthos e igualmente imperativa e vinculante, } \\
\text { ou então não será nada (GOEBBELS, } 2020 \\
\text { grifos nossos).13 }\end{array}$ \\
\hline
\end{tabular}

Fonte: Elaborado pelos autores a partir de registros do Canal Poder 360 (2020) e da BBC (2020).

A repercussão negativa do discurso do secretário de cultura foi, sobretudo, por conta desse trecho, no qual a semelhança com o discurso nazista ficou mais evidente, reforçada, como dito anteriormente, pela atmosfera estética da produção audiovisual, desde a disposição dos objetos em cena até a leitura pausada do secretário, sem esquecer da trilha sonora de Richard Wagner, uma das favoritas de Hitler.

A paráfrase como um todo é significativa, mas é preciso destacar o trecho "profundamente vinculada às aspirações do nosso povo". O povo não aparece aqui como representativo de todo e qualquer brasileiro, considerando que a mensagem transmitida em nenhum momento fala em diversidade, pluralidade, mistura e todas as palavras que vêm à cabeça quando se pensa na cultura brasileira, amplamente conhecida por essas características. 0 povo ao qual se fala se restringe ao seu eleitorado, definido por uma pesquisa da Datafolha como sendo predominantemente de homens com ensino superior completo, faixas de renda elevadas e, também, evangélicos.

\footnotetext{
13 De acordo com Peter Longerich, biográfo de Goebbels, essas foram as palavras do Ministro da Propaganda de Hitler antes de promover uma grande queima de livros considerados impróprios pelo regime, em 8 de maio de 1933 (FOGUEIRA, 2020).
} 
No Brasil e no mundo, a crise do patriarcado branco tem se convertido em agressão neofascista. Na eleição de Donald Trump14 e seus homólogos, o Brexit, percebe-se o profundo apelo emocional das campanhas que conseguiram desbancar seus adversários. Tais campanhas se opõem aos dados empiricamente comprováveis, gerando narrativas direcionadas a um passado imaginário, miticamente estabelecido ("tornar a América grande novamente"), ou se direcionam à urgência do presente, como expresso no slogan do Brexit (Reassumir o controle). Pode-se, então, compreender que a necessidade de uma arte "profundamente vinculada às aspirações urgentes do nosso povo - ou então não será nada", defendida por Roberto Alvim, consiste em uma convocação para que este patriarcado branco, para o qual fala, "reassuma o controle", embora, de fato, nunca o tenha perdido. Hoje, o protagonismo e avanços dos direitos políticos e civis das "minorias" incomodam. Deste incômodo advém a ideia de "retorno", seja para os Estados Unidos da década de 1950, ou para o Brasil da década de 1970, período de ditadura militar, propaganda nacionalista, rígido controle sobre os costumes sociais, ordem imposta e autoritarismo.

Por estar (supostamente) desvinculada deste passado militarizado, a cultura atual é, segundo essa crença, uma "cultura doente" porque traz elementos que não são compatíveis ou que questionam as frágeis mitologias que sustentam a posição de poder do homem branco. Daí a necessidade de promoção de uma "política de salvação" baseada na confiança como ferramenta de uma nova cruzada, de uma "luta contra com o mal", isto é, o mal personificado no outro, diga-se, o negro, a mulher, o LGBTQIA+ e o pobre. Estes devem ser apenas admitidos como subalternos ou como complemento da "identidade branca" a partir de critérios de alteridade. Isso explica a forma como a atual extrema-direita brasileira lida com o futuro. Se o passado é glorioso e o presente traz a urgência das necessidades do momento, para o patriarcado branco, o futuro se manifesta apenas como incerteza e ansiedade, pois o futuro se coloca como um espaço aberto para o reconhecimento e realização de mais direitos de setores historicamente marginalizados, por isso a utilização do revisionismo histórico 15 como ferramenta política e a urgência em "reassumir o controle" no presente, que no Brasil quer dizer, sobretudo, frear o processo de desconstrução do machismo, do racismo, da misoginia, da homofobia, do proselitismo religioso, bem como impedir que os setores populares tenham acesso a bens de consumo e melhores condições de vida. Ou seja, reter

\footnotetext{
14 Gestão amplamente apoiada pelo atual governo brasileiro.

15 Para Roehe (2016), os primeiros movimentos "revisionistas" da História foram identificados na França, na década de 1950, a partir de uma articulação da extrema direita combalida, após a Segunda Guerra Mundial. No Brasil, percebe-se que além de rever aspectos do nazismo, tais grupos revisionistas se esforçam para forjar narrativas distorcidas do período escravagista brasileiro.
} 
possíveis movimentos de questionamento da dominação mandonista16 e patrimonialista, que se ampara em um discurso moralista, baseado em pilares como "família, religião e nação" para promover preconceitos, violências e ampliar a desigualdade entre dominados e dominantes (SCHWARCZ, 2019). Nesse sentido, a arte e a cultura não podem ser plurais, ao contrário, devem atender aos anseios de uma minoria, vendida como maioria, em mais uma estratégia discursiva identificada no trecho:

\begin{abstract}
Portanto, almejamos uma nova Arte nacional, capaz de encarnar simbolicamente os anseios desta imensa maioria da população brasileira, com artistas dotados de sensibilidade e formação intelectual, capazes de olhar fundo e perceber os movimentos que brotam do coração do Brasil, transformando-os em poderosas formas estéticas. São estas formas estéticas, geradas por uma Arte nacional que agora começará a se desenhar, que terão o poder de nos conferir, a todos, energia e impulso para avançarmos na direção da construção de uma nova e pujante civilização brasileira. (ALVIM, 2020, grifos nossos).
\end{abstract}

Assim, faz-se com que a ideia de "Arte nacional" seja um vetor de fortalecimento do discurso de campanha eleitoral, mas, agora, utilizando o poder e a verba pública para premiar aqueles que se adequarem a este projeto ideológico. A concepção de um movimento que viabilize "poderosas formas estéticas", dando impulso e energia para construção de uma "civilização brasileira”, faz emergir uma concepção vitalista da obra de arte, de inspiração nietzschiana e organicista (COELHO, 2012), também presente na obra de Jünger, que traz o entendimento da obra de arte como o lugar privilegiado de expressão da vontade e, nesse caso, é uma vontade orgânica. Desse modo, o artista desaparece na promoção de um tipo ideal, uma totalidade:

Se, por um lado, Jünger se coloca crítico do desejo de segurança burguês e da incapacidade burguesa de estabelecer um autêntico comando em meio à mobilização total, e ainda que não reivindicasse para si a identidade fascista, sua defesa de uma nova totalidade acaba se configurando num projeto de reestabelecimento de uma Ordem, tão absoluta que apresenta o caráter de uma metafísica. (COELHO, 2017, p. 260).

O discurso de Roberto Alvim parece incorporar esse ideário, quando fala em "Arte nacional" para "construção de uma nova e pujante civilização brasileira", ou seja, uma

\footnotetext{
16 Segundo Arruda (2013, p. 2), o conceito de mandonismo é, por vezes, confundido com o de coronelismo, mas "é característica básica do poder local na América Latina, onde as leis não atingiam a população rural e o senhor agrário (senhor de engenho, coronel, caudilho etc) era mandatário quase absoluto de suas terras".
} 
totalidade que não permite dissenso, uma nova ordem que exige conformação a um tipo (Gestalt), em que a arte deixa de ser arte e passa a ser propaganda.

\begin{abstract}
É neste espírito que o Governo Federal tem o orgulho de lançar os seguintes Prêmios Nacionais de fomento às artes [...] O Prêmio Nacional das Artes gerará milhares de empregos, assim como uma ampla capacitação profissional e formação de público, configurando um panorama das maiores realizações artísticas oriundas das 5 regiões do Brasil. Trata-se de um marco histórico nas Artes brasileiras, de relevância imensurável, e sua implementação e perpetuação ao longo dos próximos anos irá redefinir a qualidade da produção cultural em nosso país. (ALVIM, 2020, grifos nossos).
\end{abstract}

O Prêmio Nacional das Artes seria, na realidade, um "projeto civilizacional" para construção de um Brasil mitificado, desconsiderando sua constituição histórica e social, de uma sociedade muito rica e diversa. Este projeto visa modificar o que se tem ou "redefinir a qualidade", colocando a atual produção artística nacional em um patamar de inferioridade ao que se pretende construir. Ao partir de tal pressuposto, o projeto confronta, inclusive, as normas programáticas da Constituição Federal promulgada em 1988, que garante o pleno exercício dos direitos culturais e protege as manifestações das culturas populares, indígenas e afro-brasileiras (BRASIL, 2020).

Cabe ao Estado oferecer e garantir os meios para que todos os brasileiros tenham acesso à cultura e tenham sua cultura valorizada. Não cabe ao Estado a construção de um "tipo ideal brasileiro", por intermédio de políticas de fomento à produção cultural baseado em um imaginário de "Arte Nacional". Basta observar a Constituição Federal, art. 216-A, que afirma que o Sistema Nacional de Cultura:

[...] institui um processo de gestão e promoção conjunta de políticas públicas de cultura, democráticas e permanentes, pactuadas entre os entes da Federação e a sociedade, tendo por objetivo o desenvolvimento humano, social e econômico com pleno exercício dos direitos culturais. (BRASIL, 2020).

Além disso, o $§ 1^{\circ}$ do artigo citado estabelece os princípios que orientam o Sistema Nacional de Cultura e o Plano Nacional de Cultura, onde destacam-se: "(I) a diversidade das expressões culturais [...] (X) a democratização dos processos decisórios, (XI) a descentralização articulada e pactuada da gestão, dos recursos e das ações" (BRASIL, 2020). Diversidade e a promoção democrática da cultura são orientações nucleares na criação e 
promoção de políticas públicas para o campo cultural, esses termos não aparecem direta ou indiretamente, em nenhum momento, no discurso de Roberto Alvim. Em seus lugares estão Deus e a família, elementos que fazem parte de um vocabulário moral e religioso, incompatíveis com o espírito público que o Estado laico, assegurado pela Constituição Federal, deve perseguir.

\section{0 percurso até aqui}

Fazendo um resgate histórico de comportamentos do atual presidente Jair Bolsonaro, responsável pela nomeação de Roberto Alvim para o cargo de secretário de cultura (após a extinção do Ministério da Cultura e transformação em uma secretaria, vinculada ao Ministério da Cidadania), é possível compreender a base de pensamento da atual gestão acerca do valor da cultura e do respeito às diferenças e diversidades étnicas e culturais. No ano de 2017, por exemplo, no clube Hebraica, do Rio de Janeiro, Jair Bolsonaro reafirmou em discurso um perfil que pode ser interpretado como segregacionista, conforme é possível observar nos trechos selecionados abaixo:

[...] Alguém já viu um japonês pedindo esmola por aí? Porque é uma raça que tem vergonha na cara! [aplausos e gritos]

Pare de querer essas minorias nas tetas de quem trabalha! Não é nas tetas do governo não! Que o dinheiro não é do governo não! O dinheiro é nosso! Pode ter certeza se eu chegar lá não vai ter dinheiro pra ONG! [pausa seguida de aplausos] Esses inúteis vão ter que trabalhar! [aplausos e gritos]. Se eu chegar lá, no que depender de mim, todo cidadão vai ter uma arma de fogo dentro de casa! [aplausos e gritos] Não vai ter um centímetro demarcado pra reserva indígena ou pra quilombola! [gritos e aplausos]

Eu tenho um quinto também, o quinto eu dei uma fraquejada né, foram quatro homens a quinta eu dei uma fraquejada veio uma mulher, [risos] ela tem seis anos de idade e foi feita sem aditivos. [risos]

Isso aqui é só reserva indígena [mostrando o mapa], tá faltando quilombolas, outra coisa que é brincadeira... eu fui num quilombola em El Dourado Paulista, olha... o... o afrodescendente mais leve lá, pesava sete arrobas [risos]. Não fazem nada! Eu acho que nem pra procriador serve mais! (BOLSONARO, 2017, grifos nossos).

É possível notar que, desde antes da eleição, já havia sido esboçado um contexto favorável para a promoção de discursos que se assemelham com o de regimes fascistas e, 
mais especificamente, o nazismo17. Embora o discurso acima tenha repercutido, não teve a mesma reverberação se comparado ao discurso de Roberto Alvim. Isso, em parte, explica-se pelo fato do segundo ter sido divulgado nos canais oficiais de comunicação do governo e, também, pelo discurso de Roberto Alvim ter parafraseado de forma muito aproximada o discurso de Joseph Goebbels - ministro da propaganda nazista -, tocando em um tema historicamente sensível18, especialmente para setores influentes que apoiam o governo, que tem buscado uma filiação simbólica com Estados Unidos e Israel19. A imprensa chegou a afirmar que a exoneração de Roberto Alvim se deu, em grande parte, por pressão desses setores de apoio do atual governo.

Vale relembrar que durante o discurso acima destacado do então candidato Jair Bolsonaro, as pessoas que lá estavam riram e aplaudiram, ignorando o fato de que o racismo foi elemento constitutivo do regime nazista, que perseguiu e exterminou populações (não apenas os judeus), baseando-se em critérios de supremacia racial para desumanização do outro. 0 discurso racista elege o critério da "raça" para hierarquização entre os povos. 0 racismo é um fenômeno eminentemente moderno, uma transmutação do racialismo do século XVI, que compreendia a humanidade a partir de raças diferentes. Com o iluminismo, o racialismo passou a definir raça segundo as características físicas comuns de determinados agrupamentos humanos, incorporando para além do fenótipo, uma perspectiva moral com repercussão na cultura e no comportamento. Com a Antropologia Física, a Frenologia, e o desenvolvimento de teorias eugênicas, lastreadas pela Medicina e pela Criminologia, o racismo adquire status científico20, tendo na obra de Cesare Lombroso (1835-1909), criador da Antropologia Criminal, uma de suas principais referências. Enquanto o racialismo consiste no entendimento e estudo de diferentes raças humanas, o racismo aplica essas teorias,

\footnotetext{
17 Recentemente, a antropóloga Adriana Dias encontrou uma carta de Bolsonaro publicada em sites neonazistas, no ano de 2004. 18 A "Shoah" como paradigma do drama humanitário é uma das heranças da política de memória da Segunda Guerra Mundial, em consonância com a Declaração Universal dos Direitos Humanos e a criação do Estado de Israel em território palestino. 0 holocausto judeu ocupa lugar de destaque na discussão relativa a crimes de guerra, genocídio e outras violações de direitos humanos. Ainda que vários outros povos tenham sofrido com a violência da guerra e, antes disso, com a violência colonial, o povo judeu conta com capital financeiro e intelectual para manter em evidência seu sofrimento. Nesse sentido, é preciso compreender a instrumentalização política da memória do holocausto: "A Shoah quer assinalar a singularidade absoluta do martírio judeu em relação a todas as outras vítimas coletivas da história humana. Esta singularidade absoluta da infelicidade judaica assegura a singularidade absoluta de Israel ente as nações e constitui sua justificativa para escapar às leis internacionais. Israel porta doravante em si a Shoah, que legitima todas as suas ações. A lembrança do martírio judaico passado oculta o calvário presente do povo palestino" (MORIN, 2007, p. 121).

19 As principais viagens internacionais de Jair Bolsonaro, antes e depois de eleito, replicaram o caminho de Donald Trump, com destaque para suas viagens ao Estado de Israel para encontrar o primeiro-ministro Benjamin Netanyahu.

20 Antes do Homem delinquente (1876), de Lombroso, Arthur de Gobineau (1816-1882), autor do Ensaio sobre a desigualdade das raças humanas (1853-1855), considerava que a história da humanidade só poderia ser entendida pela evolução das raças. Defendia que a mestiçagem foi indispensável (lei da atração) para o aparecimento de civilizações, mas a repulsa desempenhou um papel importante numa parte da humanidade que nunca iria "civilizar-se". Assim, a lei da atração não deveria ser usada em excesso, pois as raças se degenerariam, fazendo-as entrar em declínio (DE FONTETTE, 2012).
} 
acreditando na hierarquia entre "raças", criando mecanismos sociais, políticos e epistemológicos para reprimir e hostilizar raças consideradas inferiores. Em uma perspectiva racista, um povo é superior a outro devido sua raça, que tem características específicas e "naturais". Nesse sentido, um povo pode e deve ser sacrificado ou escravizado porque é menos humano (ou sequer é humano); quando é minoria apresenta um risco de contágio para maioria, isto é, de degeneração e declínio civilizacional. Como aponta Sueli Carneiro (2011, p. 15): "Se alguns estão consolidados no imaginário social como portadores de humanidade incompleta, torna-se natural que não participem igualitariamente do gozo pleno dos direitos humanos".

Em um contexto de agressão fascista, as minorias precisam ser afastadas ("que se curvem à maioria"), uma vez que comprometem a ideia de funcionamento orgânico da sociedade, que é uma perspectiva biologizante da política, por isso, o ataque furioso contra as minorais, atribuindo a elas um caráter parasitário. Então, todos os problemas sociais são direcionados a grupos específicos (quilombolas, indígenas e seus territórios) que, no discurso de Bolsonaro, aparecem como um impedimento para exploração de riquezas, um dos motivos que justificaria o atraso econômico do Brasil, aliado a preguiça e indolência dos quilombolas que estão tão pesados de não trabalhar. Este discurso não é inaugural, segue uma longa tradição do racismo institucionalizado no Brasil que, por mais que não se queira admitir, estrutura as relações sociais e a forma como o corpo negro é representado, sempre como perigoso e indesejado. E, quando admitido, o negro está em posição de subalternidade ou, nas fantasias fetichistas da classe média brasileira, como elemento de virilidade e de violador nas relações interraciais. Isso leva ao ponto seguinte: a obsessão com a sexualidade e com o masculino.

0 atual presidente do Brasil foi eleito em meio a declarações polêmicas tanto com relação às mulheres quanto aos LGBTQIA+. Nessas afirmações, o feminino é representado como sinal de fraqueza. Historicamente, foi construída e difundida a ideia de família tradicional, em que a mulher é apresentada como "sexo frágil", inferior, dominada pela emoção, ao passo que o homem seria, nesse imaginário, dotado de razão, devendo conduzir a relação e exercer o papel de provedor da família, confinando a mulher ao ambiente doméstico, responsabilizando-a pela educação dos filhos e a organização do lar. Esta percepção de fragilidade e do papel feminino na relação familiar era, inclusive, reforçada pelo discurso médico no fim do século XIX e início do século XX (MATOS, 2003). 
A ideia de restauração da família tradicional brasileira e a necessidade de reforçar o padrão heteronormativo de comportamento visa questionar, ou melhor, deslegitimar do ponto de vista moral, o processo de emancipação feminina e as conquistas de direitos por parte da comunidade LGBTQIA+, impulsionados pelas discussões cada vez mais constantes e necessárias dos papéis de gênero e de sexualidade na sociedade. Além do protagonismo feminino em diversas frentes, o reconhecimento de direitos da pessoa homoafetiva e/ou pessoa transgênero tem afetado sobremaneira a sociedade patriarcal, demandando um reforço dessa identidade, seja por meio da criação de mitologias, como a ideia de "ideologia de gênero", ou pelo cultivo de um comportamento agressivo, associado ao discurso de ódio contra minorias, escancarando diferentes formas de discriminações e violências simbólicas há muito presentes na sociedade, mas que agora encontraram o catalizador e o terreno fértil para por em marcha uma política de (re)sentimentos.

Percebe-se, com isso, que a crise democrática vivenciada, atualmente, é também uma crise de representatividade. Ela favoreceu a ascensão de figuras políticas que têm como base discursiva o combate aos avanços sociais por parte de camadas da sociedade que sempre sofreram negligências sociais e políticas. Como explica Castells (2018):

Vários grupos étnicos e culturais (afro-americanos, latinos, chicanos, indígenas americanos, asiáticos de diferentes nações e etnias, mulheres, lésbicas, gays, transexuais e outros múltiplos conjuntos) têm afirmado sua identidade específica e lutado por seus direitos. De repente, os homens brancos perceberam que ninguém falava de sua identidade. E mais, que as outras identidades se definiam como contestadoras da identidade supostamente dominante: a identidade patriarcal do homem branco. Que, por ser a identidade alfa, foi superada e negada como identidade. Desse sentimento de exclusão das manifestações culturais dominantes e das categorias protegidas em termos de direitos especiais, surgia a necessidade de uma afirmação dos esquecidos da política identitária: o homem branco. [...] Nesse caldo de cultura floresceram grupos racistas, neonazistas e antissemitas, que haviam ficado na penumbra e viram chegar seu momento. (CASTELLS, 2018, p. 51).

Retornando ao discurso de Roberto Alvim, a promoção de uma "Arte Nacional" seria a estratégia capaz de transformar esse sentimento do patriarcado em uma "poderosa forma estética", baseada na "nobreza dos mitos fundantes" e que exalta a Pátria, a família e a relação com Deus. Trava-se, neste discurso, uma luta do bem contra o mal, exigindo:

Voltar à nação como comunidade cultural da qual são excluídos os que não compartilham valores definidos como originários. Voltar à raça, como fronteira aparente do direito ancestral da etnia majoritária. Voltar, também, 
à família patriarcal, como instituição de primeira proteção cotidiana diante de um mundo em caos. Voltar a Deus como fundamento. (CASTELLS, 2018, p. 38).

Em um contexto de desconfiança nos partidos políticos e nas instituições, é fortalecida uma política da crença, na qual as pessoas buscam novos atores políticos (algumas vezes, nem tão novos assim e, neste caso, trazem apenas uma roupagem distinta) nos quais seja possível crer. Nesse sentido, os segmentos sociais reagiram, impulsionados pelo medo da vulnerabilidade e pelo acúmulo de frustrações. Vale lembrar, que a sociedade brasileira enfrentou no segundo governo de Dilma Rousseff, uma recessão, em parte ocasionada pela situação econômica internacional, entre o final de 2011 e o início de 2012, marcada pela crise da Zona do Euro, pela desaceleração da economia chinesa e uma recuperação lenta dos Estados Unidos, com impacto negativo na atividade doméstica. "O comportamento da economia brasileira passou de desaceleração, ao longo do primeiro mandato de Dilma, para uma recessão a partir do primeiro ano do segundo mandato, o que intensificou o debate a respeito do papel da política fiscal sobre o ritmo de atividade" (DWECK; TEIXEIRA, 2017, p. 2). Vivenciando este momento de crise econômica, a sociedade se mobilizou ao redor de figuras messiânicas e que prometiam a volta ao idealizado passado "glorioso". Esta idealização do passado é construída a partir do fortalecimento de discursos racistas, machistas e elitistas, que remontam a um período de menos questionamentos acerca dos direitos sociais. Há, também, um reforço da ideia de combate à corrupção, atribuindo a esta, os problemas econômicos vivenciados pelo país, que, como já foi explicado anteriormente, na realidade, estavam ligados a questões econômicas mais amplas. Sendo assim, estas figuras se projetam como paladinos no combate à corrupção, como força moralizadora necessária em uma sociedade corrompida e que beira à falência.

Os setores populares precisavam de respostas imediatas para problemas concretos (emprego e segurança pública). Os setores médios da sociedade temiam não manter o padrão de consumo que adquiriram na última década e que permitiu ao brasileiro da classe média se vincular a um discurso elitista, ainda que as flutuações da economia atinjam esses dois setores de maneira diferente. Enquanto isso, os mais ricos se incomodaram com os avanços dos setores mais populares, que passaram a ocupar espaços restritos anteriormente, como as vagas nas universidades públicas e, até mesmo, os aeroportos. A solução restauradora da ordem vendida à sociedade foi o impeachment da presidente Dilma Rousseff, em 2016, que teve como consequência a ascensão imediata da direita, na figura do vice-presidente, Michel 
Temer (MDB) e, posteriormente, da extrema-direita, com a eleição de Jair Bolsonaro. Faz-se importante destacar que não se nega a ocorrência de corrupção, o que se aponta, neste artigo, é que houve a espetacularização dessa corrupção e uso eleitoreiro dela.

\section{Considerações finais}

Conclui-se que a crise de legitimidade democrática, que tem caracterizado as democracias liberais - no caso do Brasil, agravada em 2016 -, possibilitou mobilizar uma parcela significativa da população por meio de um discurso baseado no medo e no ódio e, além disso, usando uma ideia de política que pretende "voltar ao início", mesmo espírito que guia a ideia de uma "Arte Nacional enraizada na nobreza de nossos mitos fundantes". Esse entendimento de "restauração" da Cultura estava presente da Alemanha após a Primeira Guerra Mundial (1914-1918), momento em que o conservadorismo ganhou força, negando, por um lado, a democracia liberal e o caráter desagregador do capitalismo e, por outro, o comunismo internacionalista soviético. Como alertava Faye (2009), o conservadorismo se diferencia do pensamento revolucionário por não confiar na criação rápida e convulsiva. Para ele, a revolução ascende da traição e o Estado significaria a conservação.

Buscou-se, então, no nacionalismo, fundamento para construção de uma terceira via, recorrendo ao neorromantismo e ao movimento volkish 21 como quadro de referência. 0 pensamento reacionário alemão do século XIX e seus elementos constitutivos - elitismo, nacionalismo, racismo, autoritarismo - ganharam uma nova força no cenário do entre guerras, convertendo-se em agressão fascista, levando a cabo uma ideia de mobilização total do povo (volk) capaz superar a crise política e espiritual da Alemanha sob a autoridade do Führer (líder), que comandaria a nação alemã na restauração de seu passado glorioso representado pelo Sacro Império Romano da Nação Germânica, na figura de Carlos Magno (I Reich) e pela unificação do Império Alemão, em 1871, com Otto von Bismarck (II Reich) inaugurando o III Reich com Hitler.

Há muitas diferenças entre o Brasil dos últimos tempos e a Alemanha do entreguerras. Por óbvio, é um erro de análise reduzir um processo a outro. No entanto, é igualmente um

\footnotetext{
210 termo significa "étnico", derivado de "volk" (povo), que abarca noções como "raça”, "tribo", "nação”, na precisa afirmação de Michael Mann (2008. p. 18): "A nação era essencialmente uma e indivisível, uma entidade viva e palpitante, definida como 'integral' ou 'orgânica'. Ser alemão, italiano, ou francês, sustentavam os fascistas, significava muito mais do que viver em num espaço geográfico; significava algo que os estrangeiros não podiam avaliar, enfatiza Mosse, a versão alemã da nação diferia da europeia do sul, sendo tão racial quanto cultural. Recorria mais ao darwinismo social, ao antissemitismo e a outras correntes teóricas raciais do século XIX para formar um Volk, uma unidade étnico-cultural singular que transcendia qualquer possibilidade de conflito em seu interior, mas ao mesmo tempo erguendo limites mais altos contra os outros povos".
} 
equívoco deixar de apontar as inúmeras semelhanças, que, por vezes, apresentam-se de forma mais explícita - como no discurso de Roberto Alvim - e outras de forma sutil. A ascensão de Hitler conjugou uma série de fatores que já estavam presentes na Alemanha antes da guerra, mas que tiveram uma nova configuração após as imposições do Tratado de Versalhes. Entre 1922 e 1945, o fascismo ganha força em toda Europa, com destaque para Alemanha e Itália, como processo de crítica contundente ao liberalismo, ao mesmo tempo que marcava oposição ao regime comunista soviético. Suas características principais eram: a mobilização das massas, seu papel contrarrevolucionário (ou revolucionário conservador como já abordamos), "a ênfase em valores tradicionais em contraposição à modernidade e a recriação do passado e invenção de tradições" (SILVA; SILVA, 2015, p. 142). Soma-se a isso uma profunda militarização da sociedade promovida por meio de intensa propaganda. Podese entender o fenômeno a partir de uma perspectiva psicológica, como fez Wilhelm Reich, em 1933 - A Psicologia de Massas do Fascismo - definindo o fascismo como uma psicologia política das massas frustradas (REICH, 1933). Para ele, o masoquismo, somado à repressão às leis naturais da vida e do amor, submete as massas a um regime assentado na força. Desse modo, o ser humano reprimido acaba canalizando o impulso de liberdade para a devoção da imagem de uma liderança. 0 regime fascista não se estabelece por ter qualidades políticas, mas por atender aos instintos psicossociais das massas (SILVA; SILVA, 2015).

Diante do exposto, percebe-se a importância da exaltação do masculino e da virilidade como fundamento de uma sociedade reprimida que, para combater inimigos reais e/ou imaginários (minorias, o fantasma do comunismo, "globalismo" etc.), recorre para o reforço da autoridade patriarcal, na figura do pather (pai protetor), capaz de canalizar esse desejo de revolta e libertação contra os inimigos da nação e do "povo", o que justificaria, no campo cultural: "uma nova Arte nacional, capaz de encarnar simbolicamente os anseios desta imensa maioria da população brasileira". Por fim, nesse contexto, a luta no campo cultural é reduzida a termos dicotômicos de bem x mal, sagrado x profano, amigo x inimigo, como, também, tem sido na política. 


\section{Referências}

ALVIM, Roberto. Secretário da cultura, Roberto Alvim cita ministro nazista em pronunciamento. Canal do Poder 360 no Youtube, 2020.

ARRUDA, Luiz Gustavo Lima. Apontamentos sobre mandonismo, coronelismo e clientelismo: continuando o debate conceitual. In: SIMPÓSIO NACIONAL DE HISTÓRIA, 27., 2013, Natal. Anais [...]. São Paulo: Associação Nacional de História, 2013. p. 1-18.

AUTHIER-REVUZ, J. Heterogeneidade(s) enunciativa(s). Caderno de Estudos Linguísticos, Campinas, n. 19, p. 25-42, dez. 1990.

BOLSONARO, Jair Messias. 0 fascismo de Bolsonaro na hebraica - piores momentos. Canal Coletivo Tupinambá no Youtube, $10 \mathrm{abr}$, 2017. Disponível em: https://www.youtube.com/watch?v=uF2EzmYSYz0. Acesso em 02/11/2021..

BOURDIEU, Pierre. Estrategias de reproducción y modos de dominación.

Colección Pedagógica Universitaria, Vera Cruz, n. 37/38, p. 1-21, dic. 2002.

BOURDIEU, Pierre. Os usos sociais das ciências. São Paulo: Editora Unesp, 2004.

BOURDIEU, Pierre. A dominação masculina. Rio de Janeiro: Bertrand Brasil, 2010.

BRASIL [Constituição (1988)]. Constituição da República Federativa do Brasil. Brasília, DF: Presidência da República, 2020.

BRITO, Mariza Angélica Paiva. ReVEL, Novo Hamburgo, v. 14, n. 12, ed. esp., p. 207-229, 2016.

CARNEIRO, Sueli. Racismo, sexismo e desigualdade no Brasil. São Paulo: Selo Negro, 2011.

CASTELLS, Manuel. Ruptura: a crise da democracia liberal. 1 ed. Rio de Janeiro: Zahar, 2018.

COELHO, Victor de Oliveira Pinto. A totalidade enquanto problema histórico e categoria teórica: uma abordagem a partir das obras de Humboldt, Simmel e Ernst Jünger. Revista de Teoria da História, Goiânia, ano 4, n. 8, p. 78-105, 2012.

COELHO, Victor de Oliveira Pinto. Ernst Jünger e o demônio da técnica: modernidade e reacionarismo. Topoi, Rio de Janeiro, v. 18, n. 35, p. 246-273, maio/ago. 2017.

DE FONTETTE, François. Raça e racismo. In: ALLAND, Denis; RIALS, Stéphane (Orgs.). Dicionário de cultura jurídica. São Paulo: Editora WMF Martins Fontes, 2012. p. 14911494.

DIAS, Adriana. Pesquisadora encontra carta de Bolsonaro publicada em sites neonazistas em 2004. The Intercept Brasil, 28 de julho, 2021.

DWECK, Esther; TEIXEIRA, Rodrigo Alves. A política fiscal do governo Dilma e a crise econômica. Texto para Discussão. Unicamp, Campinas, n. 303, jun. 2017. 
FAYE, Jean-Pierre. Introdução às linguagens totalitárias: teoria e transformação do relato. São Paulo: Perspectiva, 2009.

FOGUEIRA de livros e lavagem cerebral: quem foi Goebbels, ministro de Hitler parafraseado por secretário de Bolsonaro. BBC. 17 jan, 2020

FREIXO, André de Lemos. Passados privados, ou privados do passado? Nostalgia, in-diferença e as comemorações do sete de setembro brasileiro. Revista NUPEM, Campo Mourão, v. 11, n. 23, p. 59-80, maio/ago. 2019.

FOUCAULT, Michel. A arqueologia do saber. Rio de Janeiro: Forense Universitária, 1997.

FOUCAULT, Michel. A ordem do discurso. São Paulo: Edições Loyola, 2001.

GOEBBELS, Paul Joseph. In: Fogueira de livros e lavagem cerebral: quem foi Goebbels, ministro de Hitler parafraseado por secretário de Bolsonaro. BBC. 17 jan, 2020.

GUISALBERTI, Alessandro. As raízes medievais do pensamento moderno. São Paulo: Instituto Brasileiro de Filosofia e Ciência "Raimundo Lúlio", 2011.

KOSELLECK, Reinhart. Futuro passado: contribuição à semântica dos tempos históricos. Rio de Janeiro: Contraponto: Ed. PUC-Rio, 2012.

KRESS, Gunther; VAN LEEUWEN, Theo. Reading images: the grammar of visual design. London: Routledge, 2006.

JÜNGER, Ernst. A mobilização total. Tradução e notas de Vicente Sampaio. Natureza Humana, v. 4, n. 1, p. 189-216, jan./jun. 2002.

LOMBROSO, César. 0 homem delinquente. Porto Alegre, Ricardo Lenz, 2001.

MACEDO JÚNIOR, Ronaldo Porto. Carl Schmitt e a fundamentação do direito. São Paulo: Saraiva, 2011.

MARTINS, Célia. A imagem fotográfica como uma forma de comunicação e construção estética: apontamentos sobre a fotografia vencedora do World Press Photo 2010. [S. l.: s. n.], 2013.

MATOS, Maria Izilda Santos de. Delineando corpos: as representações do feminino e do masculino no discurso médico (São Paulo 1890-1930). In: MATOS, Maria Izilda Santos de; SOIHET, Rachel (org.). 0 corpo feminino em debate. São Paulo: Editora Unesp, 2003. p. 107127.

MANN, Michael. Fascistas. Rio de Janeiro: Record, 2008.

MORIN, Edgar. 0 mundo moderno e a questão judaica. Rio de Janeiro: Bertrand Brasil, 2007. 
OLIVEIRA, Marcelo Andrade Cattoni de. Direito processual constitucional. Belo Horizonte: Mandamentos, 2001.

ORLANDI, Eni Puccinelli. A Análise de discurso em suas diferentes tradições intelectuais: o Brasil. In: Seminário de Estudos em Análise de Discurso: Michel Pêcheux e a Análise de Discurso: uma relação de nunca acabar. p. 8-18, Instituto de Letras/PPG/Letras, UFRGS, Porto Alegre, RS, 2003.

REICH, Wilhelm. A psicologia de massas do fascismo. São Paulo: Martins Fontes, 1972.

ROEHE, Nara Simone. Revisionismo histórico: desafio para os direitos humanos. Revista Jurídica, Belo Horizonte, v. 9, n. 1, p. 1-23, 2016.

SCHWARCZ, Lilia Moritz. Sobre o autoritarismo brasileiro. São Paulo: Companhia das Letras, 2019.

SILVA, Kalina Vanderlei; SILVA, Maciel Henrique. Dicionário de conceitos históricos. 3. ed. São Paulo: Contexto, 2015.

VEYNE, Paul. 0 inventário das diferenças. São Paulo: Editora Brasiliense, 1983.

VAN DIJK, Teun A. Elite discourse and racism. Newbur. Park, CA: Sage Publications, Inc, 1993.

VAN DIJK, Teun A. Discurso y racismo. In: GOLDBERG, David; SOLOMOS, John (ed.). The Blackwell Companion to racial and ethnic studies. Oxford: Blackwell, 2001.

\title{
The National Arts Award promotion speech and its allusion to the German Nazi Regime
}

\begin{abstract}
The purpose of the article is to identify the similarities between the speech made by the secretary of Government Culture, Roberto Alvim, and the particularities of the Nazi regime, based on a theoretical approach aimed at understanding the discursive peculiarities. In this article, the Discourse Analysis methodology is not used, but it is supported by theoretical propositions about discursive construction to elaborate an interdisciplinary reflection, including historical and communicational aspects. The methodological procedures employed were: documentary collection, in this case, the video of the analyzed statement; decoupage and systematic bibliographic review to form the theoretical contribution of the investigation. The corpus of the analysis is, therefore, the dissemination video of the National Arts Award. Among the conclusions, there is the identification of visual and verbal elements that refer to the German totalitarian regime's discourse, including using the paraphrase resource.
\end{abstract}




\section{Keywords}

Discourse; Nazism; Fascism; Brazil's secretary of culture; Roberto

Alvim

\section{Autoria para correspondência}

Paulo Victor Arouche Costa Leite

pauloarouche@hotmail.com

Ingrid Pereira de Assis

ingrid.p.assis@hotmail.com

\section{Como citar}

ASSIS, Ingrid Pereira; LEITE, Paulo Victor Arouche Costa. O discurso de promoção do Prêmio Nacional das Artes e sua alusão ao regime nazista alemão. Intexto, Porto Alegre, n. 53, e-106517, 2022. DOI: http://dx.doi.org/10.19132/1807-8583202253.106517

Recebido em 15/08/2020

Aceito em 20/09/2021 